\title{
A proposition for the diagnosis and treatment of gastro-oesophageal reflux disease in children: a report from a working group on gastro-oesophageal reflux disease*
} \author{
I.Polanco ${ }^{20}$, B.K. Sandhu ${ }^{21}$, and J.Tolboom ${ }^{22}$ \\ ${ }^{1}$ Kaplan Hospital Rehovot, Israel \\ ${ }^{2}$ Hôpital Cantonal Universitaire, Genève, Switzerland \\ ${ }^{3}$ Hôpital Robert Debré, Paris, France \\ ${ }^{4}$ Sophia Children Hospital, Rotterdam, The Netherlands \\ ${ }^{5}$ Hôpital Universitaire Des Enfants, Bruxelles, Belgique \\ ${ }^{6}$ Universita Degli Studi di Napoli, Napoli, Italy \\ ${ }^{7}$ Hôpital Saint Vincent de Paul, Paris, France \\ ${ }^{8}$ U.Z. Gasthuisberg, Leuven, Belgium \\ ${ }^{9}$ CHRU Lille, France \\ ${ }^{10}$ Academisch Ziekenhuis Groningen, Groningen, The Netherlands \\ ${ }^{11}$ Centro Pediatrico, Montevideo, Uruguay \\ ${ }^{12}$ Vrije Universiteit, Amsterdam, The Netherlands \\ ${ }^{13}$ Heinrich-Heine-Universität, W-4000 Düsseldorf 1, Germany \\ ${ }^{14}$ Institute of Child Health, London, Great Britain \\ ${ }^{15}$ Hôpital des Enfants Malades, Paris, France \\ ${ }^{16}$ Birmingham Maternity Hospital, Birmingham, Great Birtain \\ ${ }^{17}$ Barnkliniken, Bergen, Norway \\ ${ }^{18}$ Academisch Ziekenhuis Vrije Universiteit Brussel, Laarbeeklaan. 101, B-1090 Brussels, Belgium \\ ${ }^{19}$ Spedali Civili, 25123 Brescia, Italy \\ ${ }^{20}$ Universidad Autonoma de Madrid, Madrid, Spain \\ ${ }^{21}$ Royal Hospital St. Michaels' Hill, Bristol, Great Britain \\ ${ }^{22}$ StRadboud Academisch Ziekenhuis Nijmegen, Nijmegen, The Netherlands
}

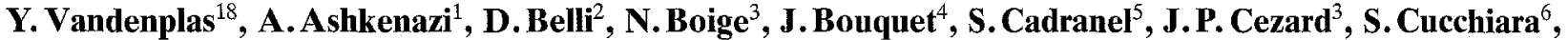
C.Dupont $^{7}$, K. Geboes ${ }^{8}$, F. Gottrand ${ }^{9}$, H.S.A.Heymans ${ }^{10}$, C.Jasinski ${ }^{11}$, C.M.F. Kneepkens ${ }^{12}$, S. Koletzko ${ }^{13}$, P. Milla ${ }^{14}$, J.F. Mougenot ${ }^{15}$, D.Nusslé ${ }^{2}$, J.Navarro ${ }^{3}$, S.J.Newell ${ }^{16}$, E. Olafsdottir ${ }^{17}$, S.Peeters ${ }^{18}$, A. Ravelli ${ }^{19}$,

Received: 23 December 1992 / Accepted: 28 January 1993

\begin{abstract}
In this paper, a Working Group on GastroOesophageal Reflux discusses recommendations for the first line diagnostic and therapeutic approach of gastrooesophageal reflux disease in infants and children. All members of the Working Group agreed that infants with uncomplicated gastro-oesophageal reflux can be safely treated before performing (expensive and often unnecessary) complementary investigations. However, the latter are mandatory if symptoms persist despite appropriate treatment. Oesophageal $\mathrm{pH}$ monitoring of long duration $(18-24 \mathrm{~h})$ is recommended as the investigation technique of choice in infants and children with atypical presentations of gastro-oesophageal reflux. Upper gastro-intestinal endoscopy in a specialised centre is the rechnique of choice in infants and children presenting with symptoms suggestive of peptic oesophagitis.
\end{abstract}

\footnotetext{
* Working group on gastro-oesophageal reflux disease of the European Society of Paediatric Gastroenterology and Nutrition Correspondence to: Y. Vandenplas
}

Abbreviation: GOR $=$ gastro-oesophageal reflux
Prokinetics, still a relatively new drug family, have already obtained a definitive place in the treatment of gastro-oesophageal reflux disease in infants and children, especially if "non-drug" treatment (positional therapy, dietary recommendations, etc.) was unsuccessful. It was the aim of the Working Group to help the paediatrician with this consensus statement and guide-lines to establish a standardised management of gastro-oesophageal reflux disease in infants and children.

\section{Introduction}

Gastro-oesophageal reflux (GOR) disease is a frequent cause of morbidity in childhood. This paper summarises the opinion of members of a Working Group of the European Society of Paediatric Gastro-enterology and Nutrition (ESPGAN) on GOR disease. Due to the recent development of new drugs and the wide availability of oesophageal $\mathrm{pH}$ monitoring, it is the opinion of the members that a proposal regarding the diagnostic and therapeutic approach would help the general paediatri- 
cian with patient management. These guidelines have the inconvenience that they are necessarily generalisations, they are not perfect, and should if necessary, be tailored for the individual patient.

Four principal aims were continuously considered: (1) the recommendations should be suitable for as large a patient population as possible (with the inconvenience that for some individual patients these recommendations will not be appropriate); (2) the recommendations should be helpful to first-line physicians (family doctors and paediatricians) in the management of infants and children with (suspected) gastro-oesophageal reflux; (3) the widespread application of these recommendations requires that the investigations and management should be as non invasive as possible; (4) attention has been given to the expenses related to a widespread application of these recommendations and their repercussion in the financial planning of health resources.

\section{Definition}

GOR is best defined as the involuntary passage of gastric contents into the oesophagus. The origin of the gastric contents can vary: saliva, ingested foods and drinks, gastric secretions, pancreatic or biliary secretions that have first refluxed into the stomach (duodeno-gastric reflux).

Various unsatisfactory terms have been used in the past, illustrating that the concentration was limited to certain aspects of the problem. In Great Britain, hiatal hernia or partial thoracic stomach was often used, emphasizing an anatomical aspect [8]. Chalasia was a popular term in North America, indicating that GOR is often related to a lax lower oesophageal sphincter, thus a functional defect that occurs so frequently that it is often considered as physiological in infants [5]. GOR does not specify any specific aetiology and is the preferred term. The definition of pathological GOR has been discussed in the previous Consensus Statement of this Working Group [43].

Vomiting is used as a synonym for emesis, and means that the refluxed material comes out of the mouth "with a certain degree of strength" or "more or less vigorous$1 y "$, usually involuntary and with sensation of nausea. Regurgitation is used if the reflux dribbles effortlessly out of the mouth, and is mostly restricted to infancy (birth-12 months). Rumination means the patients chews and swallows the refluxed gastric contents, and implies that at least part of the refluxes occurs effortless and voluntarily.

\section{Clinical presentation}

Symptoms of reflux may be observed in normal individuals, but in those cases they ar only observed incidentally, and they occur more often and are more severe in pathological situations. Reflux disease is a matter of quantity of reflux: healthy and sick people do not differ in the presence or absence of reflux, but in its frequency and intensity, and in the presence of associated symptoms
Table 1. Symptoms of GOR disease

A. Oesophageal manifestations

Specific symptoms

Regurgitation

Nausea

Vomiting

Symptoms possibly related to vomiting or complications of $G O R^{a}$

Symptoms related to anaemia (iron deficiency anaemia)

Haematemesis and melaena

Dysphagia (as a symptom of oesophagitis or due to stricture formation)

Weight loss and/or failure to thrive

Epigastric or retrosternal pain

"Non-cardiac angina-like" chest pain

Pyrosis or heartburn, pharyngeal burning

Belching, postprandial fulness

Irritable oesophagus

General irritability (infants)

\section{B. Unusual presentations}

GOR related to chronic respiratory disease (bronchitis, asthma, laryngitis, pharyngitis, etc. $)^{b}$

Asthma (caused by GOR) ${ }^{b}$

GOR caused by asthma (CARA) ${ }^{\mathrm{b}}$

Cystic fibrosis [13]

Sandifer Sutcliffe syndrome

Rumination

Apnoea, apparent life threatening event and sudden infant death syndrome [24]

C. Associated to congenital and/or central nervous system abnormalities

(intracranial tumours, cerebral palsy, psychomotor retardation)

${ }^{a}$ A number of these symptoms may also be caused by other mechanisms

${ }^{b}$ According to some authors, these associations are still speculative

[3]. Most of the clinical problems related to GOR are caused by excessive passage of (acid) gastric contents into the oesophagus. The usual manifestations and unusual presentations of GOR disease are listed in Table 1. Infants with a Roviralta Astoul syndrome have pyloric stenosis associated with hiatal hernia.

Vomiting is the most common symptom of "primary" GOR disease but is of course also a manifestation of many other diseases. Such "secondary" GOR may for example occur in infections (urinary tract infection, gastro-enteritis, etc.), metabolic disorders and food allergy. "Secondary" GOR is not discussed in this paper. It is obvious that in "primary" GOR-disease antireflux treatment is mandatory, and that in "secondary" GOR-disease the primary disease should be treated, and not the GOR itself. Anatomical or functional abnormalities lead to an increased incidence and duration of GOR and thus increased emesis (primary GOR). "Secondary" GOR or vomiting is the result of a stimulation of the vomiting centre in the dorsolateral reticular formation by all kinds of efferent impulses (visual stimuli, the olfactory epithelium, labyrinths, pharynx, gastro-intestinal and urinary tracts, testes,...).

In recent years there has been a tendency to relate a wide range of diseases or symptoms to GOR. Examples 
are as varied as chronic otitis, dental enamel etching, halitosis (bad smelling breath), globus sensation, and laryngeal lesions, which all are reported in patients with GOR. A major shortcoming of most of these reports is that there was no attempt to establish a clear causal and temporal relationship between both phenomena.

\section{Therapeutic approach}

Therapeutic approaches range from cheap and easy to expensive and complex. Considering both the experience of the members of the Working Group and the literature, a schematic approach is presented (Table 2). All recommendations do not necessarily have to be prescribed for each patient. The Table 2 is cumulative: i.e. phase 2 therapy consists of phase 1 treatment and the specific recommendations listed under phase 2 .

\section{Phase 1 treatment}

Phase 1. A. positional treatment. The influence of position on the incidence and duration of GOR episodes has been demonstrated in adults, children and infants both in asymptomatic healthy controls and symptomatic individuals. Orenstein et al. [33] demonstrated that infants had up to four times more reflux episodes in a chalasia chair (a previously widely applied treatment) than when lying prone. The $30^{\circ}$ prone reversed Trendelenburg position is nowadays generally recommended and accepted as an essential element of treatment [32]. As a result of these paediatric studies, identical treatment recommen-

Table 2. Schematic therapeutic approach

\section{Phase 1}

1 A. Position: prone reversed (head elevated) Trendelenburg position $\left(30^{\circ}\right)$

1 B. Milk-thickening agents: Bean gum, St. John's bread (Nutriton, Carobel, Nestargel, Gumilk, Gelopectose)

1 C. Dietary recommendations Increased frequency, small volume

1D. Alginic acid ( \pm antacid) (Gaviscon, Algicon)

Phase 2

Prokinetics: Cisapride (Prepulsid, Propulsin, Alimix) ${ }^{a}$ [If symptoms are resistant to cisapride: domperidone (Motilium), metoclopramide (Primperan), alizapride (Litican), betanechol]

Phase 3

3 A. $\mathrm{H}_{2}$-blockers: cimetidine (Tagamet), ranitidine (Zantac, Azantac, Raniplex, Zantic, Sostril) ${ }^{a}$, famotidine (Pepcidine, Pepdin, Pepdul, Ganor), etc.

3 B. "Experimental" treatment: sucralphate (Ulcogant, Keal, Ulcar), omeprazole (Losec, Logastric, Mopral, Antra), misoprostil (Cytotec), etc.

Phase 4

Surgery (Nissen fundoplication, Thal fundoplication, anterior gastropexya of Boerema, etc.)

"Now that the European markets are "open", communication would be simplified if drugs would have identical names in all countries dations have been advised in adults [25]. The prone reversed Trendelenburg position is sufficient to treat GOR in about $25 \%$ of infants with uncomplicated GOR (regurgitations). According to the personal experience of one of the members of this Working Group, positional treatment is efficient even in $75 \%$ of regurgitating babies. However, positional treatment is in practice very difficult to apply correctly in infants and rather uncomfortable for babies, since they have to be tied up in their beds or cot to prevent them from sliding down under the blankets, since an angle of $30^{\circ}$ has to be achieved and maintained.

Phase 1. B. milk-thickening agents. It is believed that the increased viscosity of thickened feeds will reduce the episodes of reflux, but it has been shown (by $\mathrm{pH}$ monitoring and scintigraphy) that their effect is unpredictable $[2,34]$. These products are mostly bean gum preparations from St. John's bread, a galactomannan (Nutriton $1 \mathrm{~g} / 100 \mathrm{ml}$, Carobel, Nestargel, Gumilk), although sodium carboxymethylcellulose can also be used for this purpose (Gelilact, $1 \mathrm{~g} / 100 \mathrm{ml}$ ). Nestargel is carob seed flour containing $3.5 \%$ calcium lactate. Gelopectose is a French product, and is a combination of pectin and cellulose. Bean gum preparations are fermented in the colon, providing a small energetic gain for the organism, and they can cause abdominal pain and diarrhoea. The use of cellulose might decrease postprandial glycaemia. Products such as cereals or rice extracts are not appropriate for thickening of the feeds, since their properties are rapidly modified (hydrolysation) in the stomach.

To thicken the foods seems a safe approach with good clinical results, since in most of the infants the observed symptoms of regurgitations and emesis decrease. However, results of investigations show that in a number of patients the number of reflux episodes do indeed decrease, but that the duration of the remaining episodes is prolonged, resulting in an almost identical reflux index (percentage of time with $\mathrm{pH}$ below 4.0) [42]. Data suggest that an impaired oesophageal motility is not only the cause of the GOR disease, but that it may also delay the clearance of the thickened refluxed material. As a result, thickened feeds may not be appropriate in patients with oesophagitis.

Phase 1. C. dietary advice. It is difficult to formulate general dietary guidelines, since a number of these recommendations have contradictory consequences. Increased frequency of feeding, for one, will increase the number of postprandial neutral refluxes, but will decrease the number of acid reflux episodes. As a consequence, dietary advice have to be tailored according to the needs of each individual patient.

\section{Increased frequency but decreased volume of feeding}

The ancient approach of decreased volume of feeding but at a higher frequency certainly has advantages (when the volume ingested is smaller, there is less volume to regurgitate), but also has disadvantages. Reflux occurs mostly during the postprandial periods: by feeding more frequently, the number of postprandial periods increases. 


\section{Low-fat high-carbohydrate formula}

Gastric emptying is enhanced with this kind of feeding (e.g. follow up formula). As a consequence, the duration of buffering of the gastric acidity is shortened, and oesophageal $\mathrm{pH}$ monitoring detects more postprandial acid reflux episodes with this kind of feeding if compared to a regular formula. The choice of feeding has to be determined individually: enhancing gastric emptying will decrease the number of reflux episodes (independent of the $\mathrm{pH}$ ), but will increase the number of acid episodes. Whatever feeding is prescribed, it should in any case suffice for the nutritional needs of the infant.

\section{Dietary advice in (older) children}

An anti-reflux regimen consists of a diet with normal to low fat, avoiding chocolate, coffee, tea, cola and other cabornated drinks, spicy foods, chilled beverages and/or food. Smoking also should be discouraged. Late evening meals and snacks should be restricted. Weight loss is a traditional component of reflux treatment in adults, but it is not recommended in children unless there is evidence of obesity. Drugs that may decrease the lower oesophageal sphincter pressure (xanthines and their derivates) should be avoided when possible.

Phase 1. D. antacids. Antacids are reported to be effective in the treatment of GOR [7,29]. Gaviscon (a combination of an antacid and sodium salt of alginic acid, 1$2 \mathrm{~g} / 100 \mathrm{ml}$ ) is as effective as antacids and appears to be relatively safe, since only a limited number of side-effects have been reported. Dimethiconum (Polysylon Gel, Lefax, Sab Simplex, Elugan) is very popular in some regions, and used as - although it is not - an antacid, and in other regions it is rather used against bloating, flatulence and infant colic (although no reliable study is available to prove that it is better than placebo for this indication). One should not forget the activity of antacids (buffering gastric acidity) when analysing results of $\mathrm{pH}$ monitoring in such patients. Occasional formation of large bezoar-like masses of agglutinated intragastric material has been reported with the use of Gaviscon, and it can increase the sodium content of the feeds to an undesirable degree especially in preterm infants $(1 \mathrm{~g}$ Gaviscon powder contains $46 \mathrm{mg}$ sodium, and the suspension contains twice this amount of sodium) [29]. Dimethiconum contains very little sodium $\left(0.036 \mathrm{mEq}\right.$ or $9.84 \mathrm{mg} \mathrm{Na}^{+}$per $15 \mathrm{~g}$ gel). Algicon has a low sodium load (but a high aluminium content as anion instead of sodium) with the same alginate amount, and a much better taste as Gaviscon.

Experience with other antacids (Gelusil, Maalox, Muthesa, Mylanta, etc.) is limited in infants.

\section{Phase 2 therapy}

Prokinetics. Cisapride (Prepulsid, Propulsin, Alimix, $0.4-1.2 \mathrm{mg} / \mathrm{kg} / \mathrm{day}$ in $3-4$ doses, mean $0.8 \mathrm{mg} / \mathrm{kg} / \mathrm{day}$ ) gives encouraging results $[22,26]$. It is a non-dopaminereceptor blocking, prokinetic drug [36]. Cisapride enhances gastro-intestinal contractile amplitude and improves antroduodenal co-ordination. It increases the lower oesophageal sphincter pressure and oesophageal contractility in normal volunteers [10] and in patients with decreased lower oesophageal sphincter pressure [9]. There is now considerable weight of evidence suggesting it is the drug of first choice in GOR. Almost all studies have shown good short- and long-term control of GOR, with improved oesophageal motility and the almost complete absence of serious side-effects. It is possible that cisapride is less effective in postprandial reflux, as reported by Holloway [20]. It should be stressed that cisapride is not an anti-emetic drug and has little effect on acute vomiting. Nevertheless, cisapride appears to be more effective than other drugs improving motility. Up to now, no serious side-effects have been reported. In our opinion, this drug can certainly be administered to treat uncomplicated GOR disease in infants before performing complementary investigations. Reported sideeffects are all minor and transient: colic, diarrhoea, headache, drowsiness. In non-responders to cisapride, other drugs (domperidone (Motilium, $1 \mathrm{mg} / \mathrm{kg} / \mathrm{day}$ ), metoclopramide (Primperan, $0.5 \mathrm{mg} / \mathrm{kg} /$ day), alizapride (Litican, $2-4 \mathrm{mg} / \mathrm{kg} / \mathrm{day}$ ), bethanechol (widely used in the United States of America but not marketed in Europe) can be considered. Side-effects are more frequent and more serious with these drugs than with cisapride $[19,42,44]$. Aggravation of symptoms with metoclopramide has been reported [27]. Domperidone is reported to be as effective as metoclopramide, and has the important advantage of causing less dystonic reactions (tremors) in babies and also less anxiety and gynaecomastia $[14,17,28,35]$. Transient gastro-intestinal pain, diarrhoea, skin rash, drowsiness, extrapyramidal reactions and increased serum prolactin levels have been reported with all these drugs (except with cisapride) [14].

\section{Phase 3 treatment}

Phase $3 \mathrm{~A}$ therapy: $\mathrm{H}_{2}$-receptor blockers. It is not useful to combine antacids such as alginic acid with acid secretion inhibitory drugs such as $\mathrm{H}_{2}$-receptor blockers. $\mathrm{H}_{2-}$ receptor blocking agents like cimetidine (Tagamet, 24 $30 \mathrm{mg} / \mathrm{kg} /$ day) and ranitidine (Zantac, $4-6 \mathrm{mg} / \mathrm{kg} /$ day IV or $10-15 \mathrm{mg} / \mathrm{kg} /$ day PO (in France this product is marketed as Azantac and Raniplex, in Germany as Zantic and Sostril)) have been used in GOR particularly when oesophageal symptoms predominate but results are equivocal $[11,21,26] . \mathrm{H}_{2}$-antagonists have the inconvenience of causing a rebound nocturnal acid secretion $[15,40,41]$. The doses for infants of new $\mathrm{H}_{2}$-receptor blockers are not known (famotidine (Pepcidine Pepdin in France, Pepdul and Ganor in Germany)), nizatidine (Calmaxid, Panaxid). The efficacy of these drugs on GOR cannot be evaluated by $\mathrm{pH}$ monitoring because they inhibit gastric acid secretion. However, endoscopy can indicate improvement of oesophagitis.

Phase $3 B$ therapy. Medical management of GOR in adults has greatly changed since it was reviewed by Bennett in 1976 [4]. Many new drugs ( $\mathrm{Na}+/ \mathrm{K}^{+}$-ATP-ase blockers, mucus protecting agents, etc.) have been developed (misoprostil (Cytotec 200), sucralphate (Ulcogant-Keal or UI- 
car in France), omeprazole (Losec, Logastric, Mopral in France, Antra in Germany, [30], etc.). Experience with these drugs is very limited in infants and children, although omeprazole is being more and more used with excellent results. Omeprazole has been shown to be effective in suppressing the acidity in patients with gastric stress ulcer(s) and also in neurologically impaired children. Sucralphate was shown to be as effective as cimetidine for oesophagitis in children [1]. The newest drugs, serotonin antagonists, are currently being evaluated in oncological patients receiving emetic chemotherapy (ondansetron (Zofran), etc.) which specifically influence the vomiting centre in the brain. The indication of serotonin antagonists is limited to vomiting induced by chemotherapy.

\section{Phase 4 therapy}

Surgical considerations in adults for anti-reflux treatment were recently reviewed by Siewert and Feussner [39]. Nissen fundoplication is the preferred procedure in a number of centres, although the number of centres preferring the Thal procedure appears to be comparable. More techniques do exist (e.g. anterior gastropexy of Boerema, etc.) and provide also good results. It is not the aim of this paper to discuss the differences between all surgical possibilities. The natural history of spontaneous improvement in infants and young children means that surgery should usually be postponed until medical therapy has been exhausted [31]. In life-threatening GOR disease or in children with pre-existing neurological disease surgery may be indicated earlier. There is, however, no excuse for persisting with ineffective medical management of a process that may result in growthstunting, chronic illness, persistent pain, oesophageal scarring, or even death [23].

\section{Suggested diagnostic and therapeutic approach for different patient groups}

Before suggesting practical approaches regarding the investigation and treatment of GOR, we would like to stress once more that vomiting or GOR is a non specific manifestation, and that either might be a symptom of an underlying disease. One should never forget to search for other causes of vomiting in unclear situations.

Four groups of patients will be discussed. First, interest is focussed on GOR disease in patients with uncomplicated GOR (mostly restricted to regurgitating infants, under 1 year of age). In a second paragraph, a proposal is made for optimum management in patients with complicated GOR disease (symptoms suggestive for oesophagitis). An approach is proposed for the management of patients with atypical presentations of GOR. The main difference between patients with uncomplicated and complicated GOR on the one side and those with atypical presentations on the other side, is that the latter do not vomit or regurgitate. In a last, short paragraph, we deal with a subgroup of these patients, severely neurologically impaired children.

\section{Patients with uncomplicated GOR}

This group of patients presents with repetitive regurgitations (and only seldom real vomiting). However, differentiation between regurgitations and vomiting or between regurgitations and rumination is sometimes difficult on clinical grounds. Most of the time, this form of presentation is restricted to infants ( $<1$ year). They have none of the complications related to GOR, such as failure to thrive or haematemesis. It is not always evident in this patient group whether the parental complaints relate to physiological regurgitations or whether regurgitation is too frequently and suggests GOR disease.

Contrary to recommendations that all infants with uncomplicated GOR be investigated [37], the Working Group advices that treatment may be started in these infants without performing complementary investigations (and this for scientific, ethic and economic reasons), since reflux disease can be diagnosed confidently in the majority of this group of patients on the basis of history and a trial of medical management (phase 1 and 2). Treatment recommendations start with "phase-1". "Phase-2" treatment can be started before investigations are performed. "Phase-3" treatment is only indicated in complicated GOR disease, after appropriate investigations of the patient.

However, if the results of the therapeutic trial are unsatisfactory, and parents persist in reporting complaints of symptoms (despite the necessary efforts trying to convince and reassure the parents about the physiologial nature of the complaints), $\mathrm{pH}$ monitoring may be performed to document the reflux (Fig. 1). If the result of this investigation is within normal ranges, GOR disease is unlikely, albeit in some cases, the diagnosis of GOR disease should be reconsidered (and attention given to "secondary" GOR) and/or other investigations should be performed to document GOR disease (e.g. echography

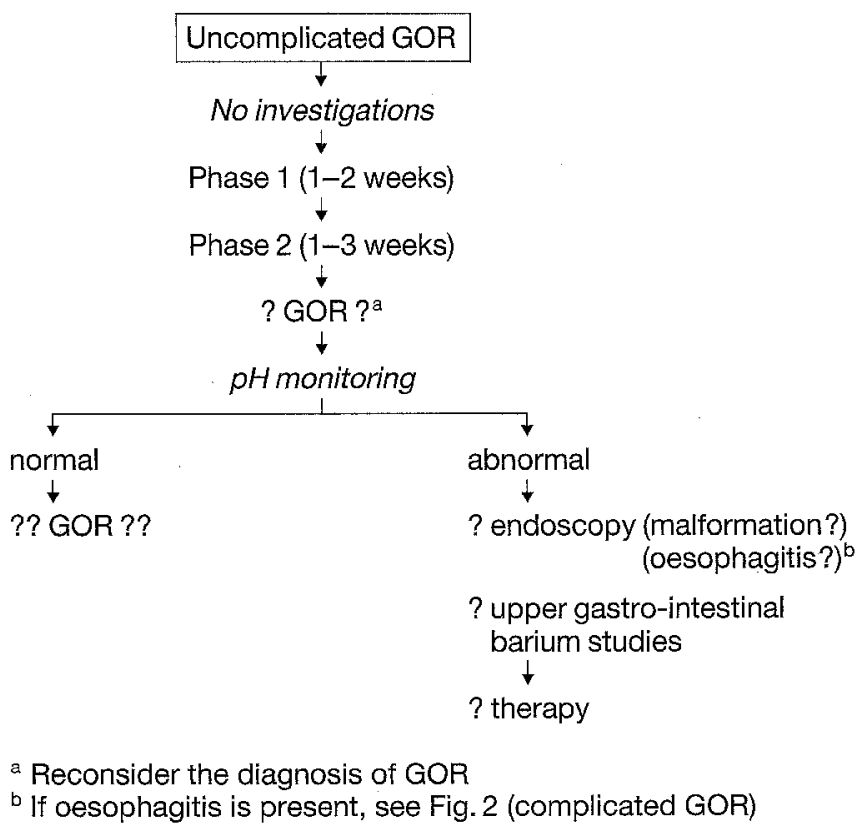

Fig. 1. Schematic diagnostic/therapeutic approach in patients with uncomplicated GOR 
or scintigraphy if non-acid reflux pathology is suspected). At this stage, the long list of "primary" disorders that may present with GOR should be (re)considered. When $\mathrm{pH}$ monitoring data are abnormal, complications of GOR-pathology could be present, and other investigations should be performed in a number of cases, including endoscopy for peptic oesophagitis or upper gastro-intestinal barium studies for anatomical malformations and swallowing disorders (Fig. 1). Manometry may be helpful to detect a (partial) achalasia of the lower oesophageal sphincter or other oesophageal motiliy disorders which might help in the understanding of failure of prokinetis. At this stage, the patient should be referred to a specialised centre.

\section{Patients suspected of oesophagitis}

These patients present with frequent vomiting and symptoms suggestive of complications (haematemesis, retrosternal and epigastric pain, etc.) (cf. Table 1).

Upper gastro-intestinal endoscopy is the investigation of first choice for the detection of peptic oesophagitis or underlying anatomical malformations (Fig. 2). This technique should only be performed by experienced and qualified paediatric gastro-enterologists and should always be a duodeno-gastro-oesophagoscopy. If the question being asked is restricted to underlying anatomical malformations, upper gastro-intestinal series can also be considered. Histological criteria for the diagnosis of oesophagitis are presented in Table 3.

Treatment should in all cases consist of "phase- 1 and -2 " therapy. Since there are reports that "minimal" oesophagitis (redness) can heal with "phase-2" alone, as a rule, it will not be necessary to administer "phase- $3 \mathrm{~A}$ " treatment $\left(\mathrm{H}_{2}\right.$-blocker). Moreover, $\mathrm{H}_{2}$-blockers do not decrease the incidence and duration of the reflux epi-

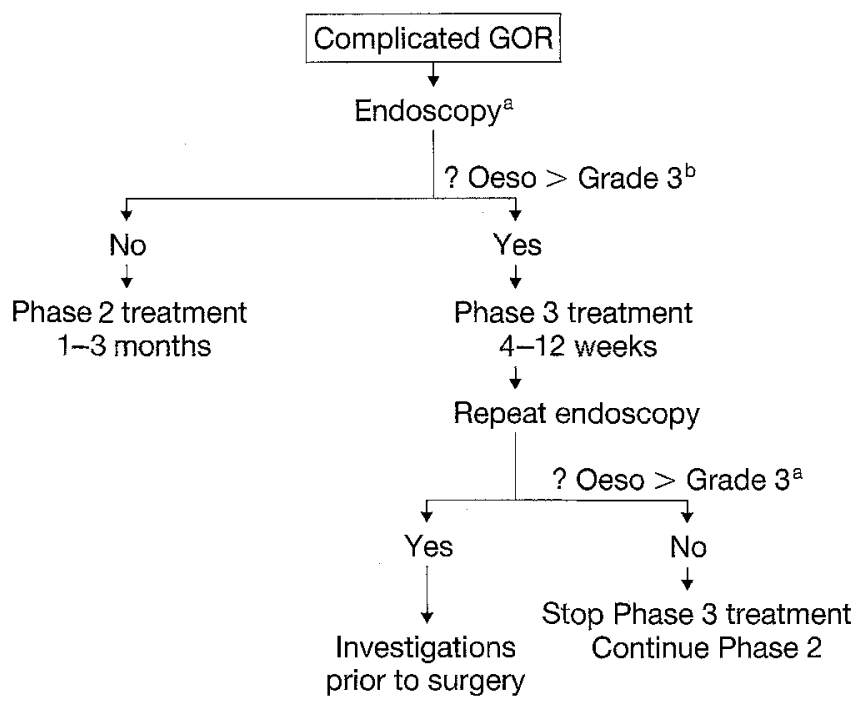

\footnotetext{
a Endoscopy is the preferred technique for oesophagitis; endoscopy and/or X-ray of oesophagus and stomach are appropriate to detect anatomical malformations

${ }^{b}$ According to criteria clarified in Table 3
}

Fig. 2. Schematic diagnostic/therapeutic approach in patients with complicated GOR
Table 3. Criteria for the diagnosis of GOR and oesophagitis on endoscopic biopsies (according to K. Geboes) [16]

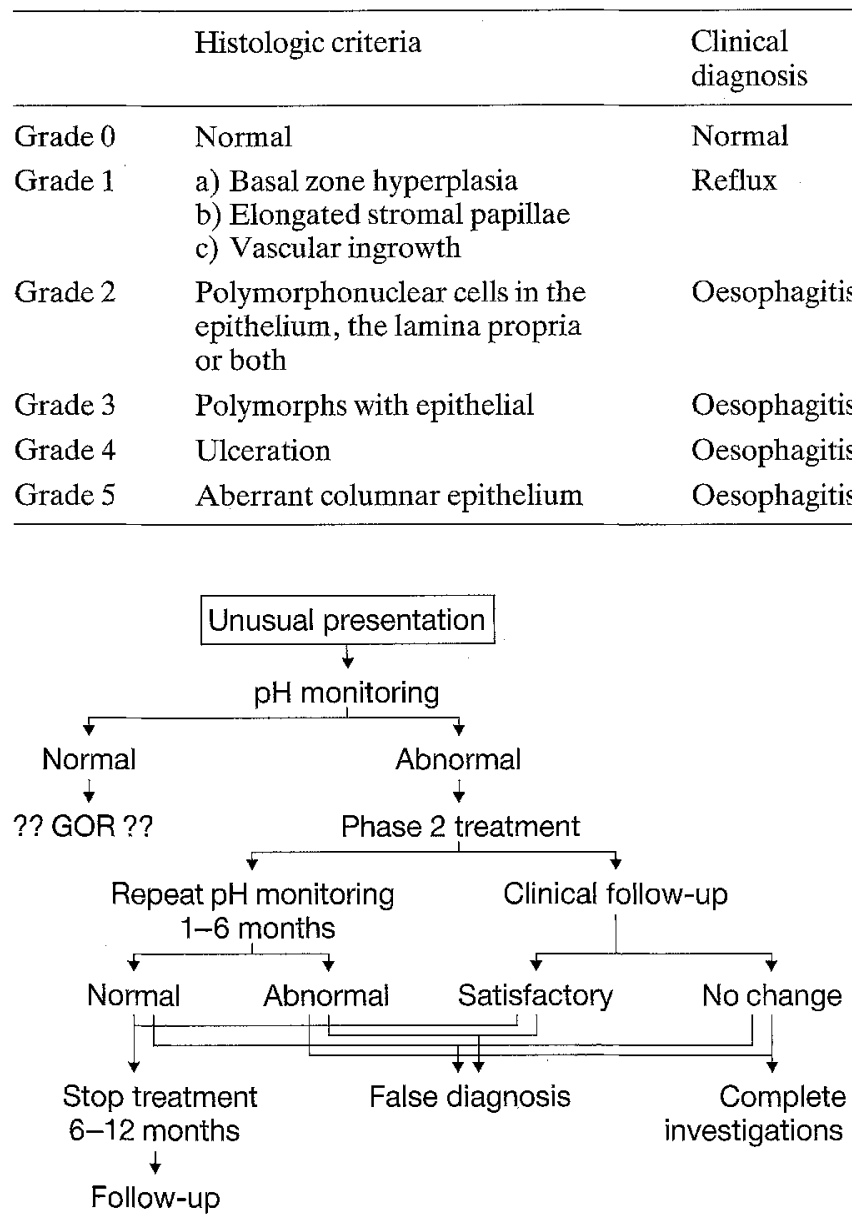

Fig. 3. Schematic diagnostic/therapeutic approach in patients with unusual presentations of GOR

sodes, they simply neutralise partially the acidity of the refluxed material. Immediate or early surgery is rarely indicated in life-threatening conditions where medical management will be of no benefit (e.g. in major grade IV oesophagitis, the efficacy of drugs like omeprazole should first be tried out (phase 3.B.)).

After about 4 to 12 weeks of treatment, a control endoscopy should be performed. If normalised, $\mathrm{H}_{2}$-blockers can be stopped. Other drugs (phase 1 and 2) can be continued for a prolonged period, depending on the clincial situation. In patients who have suffered a severe oesophagitis, we recommend a third endoscopy about 3 months after the discontinuation of the $\mathrm{H}_{2}$-blockers to recognize exacerbation.

If symptoms and/or the oesophagitis do not improve despite adequate treatment, upper gastro-intestinal series are recommended to exclude anatomical problems such as gastric volvulus, intestinal malrotation, annular pancreas, etc.

"Phase-4" therapy, surgery, although not devoid of risks and side-effects, may be inevitable in some patients, who fail to improve with "phase-3B" treatment. Surgery can be life-saving in severely affected patients (notably the neurologically impaired children with recurrent and life-threatening aspiration, etc.). Prior to sur- 
gery, a full diagnostic work-up may include upper gastro-intestinal series, manometry, endoscopy, $\mathrm{pH}$ monitoring and gastric emptying studies, all contributing to the decision to operate, and the choice of surgical procedure.

\section{Patients with unusual presentations of $G O R$}

The most obvious difference between this patient group and the patients with uncomplicated and complicated reflux, is that this patient group does not present with emesis and regurgitations (Table 1). Since these patients do not vomit, their GOR disease is "occult". Before considering GOR as a cause of the symptoms, classic causes of the manifestations need to be excluded, such as allergy in a wheezing patient, tuberculosis in a patient with chronic coughing. Unusual presentations are listed in Table 1.

If GOR disease is suspected in these infants and children, a $\mathrm{pH}$ monitoring of long duration is the examination of choice. The approach advocated by Richter and Castell in 1983 [38], in which oesophageal pH metry was suggested as the very final investigation for patients suspected of having GOR can no longer be recommended. In this group of patients, $\mathrm{pH}$ monitoring may need to be combined with simultaneous other investigations in order to relate $\mathrm{pH}$ changes to events (e.g. polysomnography in the infants presenting with an Apparent Life Threatening Event). In patients suspected of pulmonary aspiration, a scintigraphy might prove the association (although a negative scintigraphy does not exclude reflux related aspiration, and the therapeutic approach will be identical.

If $\mathrm{pH}$ monitoring is abnormal or if events are clearly related to $\mathrm{pH}$ changes, "phase-2" treatment is indicated. If the $\mathrm{pH}$ monitoring data are extremely abnormal, an endoscopy of the upper gastro-intestinal tract might be indicated to diagnose oesophagitis. Repeat $\mathrm{pH}$ monitoring under treatment conditions in this group with unusual or atypical GOR disease, combined with regular clinical observation may prove further evidence substantiating the diagnosis of GOR disease and evaluating the efficacy of treatment. Treatment can be stopped after 6-12 months, since a possible mechanism for GOR in association with unusual manifestations may be selfperpetuating ("GOR as a factor inducing GOR by itself" or "GOR perpetuates GOR"). Once reflux occurs, acid gastric contents containing pepsin and sometimes bile comes into contact with the oesophageal mucosa, which increases the oesophageal permeability to acid and makes the oesophageal mucosa much more suspetible to inflammatory changes. Oesophageal inflammation, even restricted to the lower oesophagus, impairs lower oesophageal sphincter pressure and function, and favours GOR $[12,18]$. Inflammation and dysfunction of branches of the adjacent vagus nerve also reduce the lower oesophageal sphincter pressure, favour pylorospasm and thereby inducing a vicious circle of events sustaining GOR [6].

Long-term clinical follow up of these patients is necessary.

\section{Severely neurologically impaired children}

Neurologically impaired children suffer very frequently from GOR pathology and its complications. These chil- dren are often under specialised follow-up, we will therefore only give brief recommendations. The pathophysiological mechanism of GOR in these children is particularly multifarious: the neurological disease itself (delayed oesophageal clearance and delayed gastric emptying), the fact that most of these children are bedridden (gravity), many are constipated (increased abdominal pressure), etc. GOR disease should be investigated systematically, and prolonged oesophageal $\mathrm{pH}$ monitoring is the preferred technique. Endoscopy to evaluate the condition of the oesophageal mucosa is indicated in the children with severe GOR disease. Since it might be difficult to recognise GOR disease on clinical grounds in mentally retarded children, the disease can evolve during years and lead to severe complications such as oesophageal stricture or Barrett's oesophagus. Natural resolution of GOR is less common in children with neurological disease. If phase-2 treatment (cisapride) does not provide satisfactory control of GOR-disease, therapy should be more invasive. However, it is our feeling that the efficacy of prokinetics in combination with $\mathrm{H}_{2}$-blockers or omeprazole should be evaluated prior to surgery. Proton-pump inhibitors (omeprazole) will probably appear useful in this situation, although objective paediatric data are (still) lacking. Although controlled studies in large populations are not available, it appears that a (endoscopic percutaneous) gastrostomy together with a Thal-procedure (a modified Nissen where the stomach is wrapped around $270^{\circ}$ of the lower oesophagus often performed laparoscopically), with continued cisapride may be the preferable therapy in severely neurologically impaired children. Whatever the choice of reflux therapy, appropriate investigations and treatment of GOR in these children are mandatory. There is an urgent need for blind prospective multi-centric studies on the diagnosis and treatment of GOR disease in neurologically impaired children. The opinion of centres differ regarding "best" treatment in these patients: it is not e.g. clear if a life-long treatment with prokinetics and omeprazole would be preferable to surgery.

\section{Conclusion}

The diagnostic approach of GOR disease in infants and children principally depends on its presenting features. Infants with typical symptoms of GOR without complications should be treated without prior investigation. Endoscopy, in specialised centres, is recommended if oesophagitis is suspected. Long-term oesophageal $\mathrm{pH}$ monitoring is nowadays the investigation of choice and occupies a central position in the diagnostic approach to the patient suspected of unusual or atypical manifestations of GOR disease (occult GOR disease). Only if non-drug treatment (phase 1) is unsuccessful, cisapride is recommended. Cisapride has two advantages: it is probably the most adapted drug available, and no serious ide-effects have been reported.

The authors hope that these recommendations of approach in the diagnosis and treatment of uncomplicated, severe and occult GOR disease in infants and children will help the family paediatrician in caring for his pa- 
tients with respect to these frequently encountered conditions.

\section{References}

1. Arguelles-Martin F, Gonzales-Fernandez F, Gentles MG, Navrro-Merino M (1989) Sucralfate in the treatment of reflux oesophagitis in children: preliminary results. Scand J Gastroenterol 24 [Suppl 156]: 43-47

2. Bailey DJ, Andres JM, Danek GD, Pineiro-Carrero VM (1987) Lack of efficacy of thickened feeding as treatment for gastroesophageal reflux. J Pediatr 110:187-190

3. Ballistreri WF, Farell MK (1983) Gastroesophageal reflux in infants. N Engl J Med 309:790-791

4. Bennett JR (1976) Medical management of gastro-oesophageal reflux. Clin Gastroenterol 5:175-185

5. Berenberg W, Neuhauser EDB (1950) Cardio-esophageal relaxation (chalasia) as a cause of vomiting in infants. Pediatrics $5: 414-420$

6. Boix-Ochoa J (1986) The physiological approach to the management of gastric esophageal reflux. J Pediatr Surg $21: 1932-$ 1939

7. Buts JP, Barudi C, Otte JB (1987) Double-blind controlled study on the efficacy of sodium-alginate in reducing gastroesophageal reflux assesed by $24 \mathrm{~h}$ continuous $\mathrm{pH}$ monitoring in infants and children. Eur J Pediatr 146:156-158

8. Carre IJ (1979) A historical review of the clinical consequences of hiatal hernia (partial thoracic stomach) and gastroesophageal reflux. In: Gellis SS (ed) Gastroesophageal reflux: report of the Ross Conference on pediatric research. Columbus, Ohio, pp 86-94

9. Cecatelli P (1988) Cisapride restores the decreased lower oesophageal sphincter pressure in reflux patients. Gut 29:631635

10. Corraziari E, Bontempo I, Anzini F (1984) Effect of cisapride on primary peristalsis and lower esophageal sphincter pressure. Gastroenterology 86:1054

11. Cucchiara S, Staiano A, Romaniello G, Capobianco S, Auricchio S (1984) Antacids and cimetidine tretment for gastroesophageal reflux and peptic oesophagitis. Arch Dis Child $59: 842-847$

12. Cucchiara S, Staiano A, DiLorenzo C (1987) Esophageal motor abnormalities in children with gastroesophageal reflux and peptic esophagitis. Arch Dis Child 62:454-457

13. Dab I, Malfroot A (1988) Gastroesophageal reflux: a primary defect in cystic fibrosis? Scand J Gastroenterol 23 [Suppl 143]: $15-31$

14. Deprettere A, Van Acker KJ, Du Caju MVL (1987) Increased serum prolactin but normal TSH during preolonged domperidone treatment in children. Eur J Pediatr 146:189-191

15. Fullarton GM, McLauchlan G, Macdonald A, Crean GP, McColl KEL (1989) Rebound nocturnal hypersecretion after four weeks treatment with $\mathrm{H}_{2}$-receptor antagonist. Gut 30 : $449-454$

16. Geboes K, Ectors N, Vantrappen G (1991) Inflammatory disorders of the oesophagus. Hepato-Gastroenterol 38 [Suppl 1] S26-30

17. Grill BB, Hillemeyer A, Semeraro L, McCallum R, Grybosky $J$ (1985) Effects of domperiodone therapy on symptoms and upper gastrointestinal motility in infants with gastroesophageal reflux. J Pediatr 106:311-316

18. Hillemeier AC, Grill BB, McCallum R, Gryboski J (1983) Esophageal and gastric motor abnormalities in gastroesophageal reflux during infancy. Gastroenterology 84:741-745

19. Hillemeier AC, McCallum R, Oertel R, Gryboski J (1986) Effect of bethanechol and metoclopramide on upper gastrointestinal motility in the kitten. J Pediatr Gastroenterol Nutr 5: 134-137

20. Holloway RH (1989) Effect of cisapride on postprandial gastro-oesophageal reflux. Gut 30:1187-1193
21. Johansson KE, Boeryd B, Johansson K, Tibbling L (1986) Double-blind cross-over study of ranitidine and placebo in gastroesophageal reflux disease. Scand J Gastroenterol 21:769778

22. Johnson AG, Lux G (1988) Progress in the treatment of gastrointestinal motility disorders: the role of cisapride. Excerpta Medica

23. Johnson DG (1981) Surgical selection of infants with gastroesophageal reflux. J Pediatr Surg 16 [Suppl 1]:587-594

24. Jolley G, Halpern LM, Tunell WP, Johnson DG, Sterling CE (1991) The risk of sudden infant death from gastroesophageal reflux. J Pediatr Surg 26:691-696

25. Kazlow P, Deckelbaum RJ (1988) Gastroesophageal reflux: lessons from children. Gastroenterology 94:1231-1232

26. Koelz HR (1989) Treatment of reflux esophagitis with $\mathrm{H}_{2}$ blockers, antacids, and prokinetic drugs. Scand J Gastroenterol 24 [Suppl 156]:25-36

27. Machida HM, Forbes DA, Gall DG (1988) Metoclopramide in gastroesophageal reflux. J Pediatr 112:483-487

28. Maddern GJ, Kiroff GK, Leppard PI, Jamieson GG (1986) Domperidone, metoclopramide and placebo: all give symptomatic improvement of gastro-oesophageal reflux. I Clin Gastroenterol 8:135-140

29. McHardy G (1978) A multicentric randomized clinical trial of Gaviscon in reflux esophagitis. South Med J 71:16-20

30. Nelis GF, Westerfeld BD (1990) Treatment of resistant oesophagitis in children with omeprazole. Eur J Gastroenterol Hepatol $2: 215-218$

31. Nusslé D, Genton N, Philippe P (1969) Evolution clinique et radiologique de malpositions cardio-tubérositairs non opérées du nourrisson. Acta Helv Paediatr 24:145-159

32. Orenstein SR, Whitington PF (1982) Positioning for prevention of infant gastroesophageal reflux. Pediatrics 69:768-772

33. Orenstein SR, Whitington PF, Orenstein DM (1983) The infant seat as a treatment for gastroesophage R1 reflux. N Engl J Med 309:709-710

34. Orenstein SR, Magill HL, Brooks P (1987) Thickening of feedings for therapy of gastroesophageal reflux. J Pediatr 110:181185

35. Reid M (1977) Dystonic reactions to metoclopramide (Maxilon) Ulser Med J 46:38-40

36. Reyntjens AJ, Verlinden M, Aerts T (1986) Development and clinical use of the new gastrointestinal prokinetic drugs. Drug Dev Res 8:251-261

37. Riccobana M, Maurer U, Lackner H, Uray E, Ring E (1992) The role of sonography in the evaluation of gastro-oesophageal reflux-correlation of $\mathrm{pH}$ metry. Eur J Pediatr 151:655-657

38. Richter JE, Castell DO (1983) Gastroesophageal reflux disease: pathogenesis, diagnosis and therapy. In: Castell DO, Johnson IF (eds) Esophageal function in health and disease. Elsevier, The Netherlands, pp 152-171

39. Siewert R, Feussner H (1989) Surgical considerations for antireflux therapy. Scand J Gastroenterol 24 [Suppl 168]:50-59

40. Sutphen JL, Dillard VL (1988) Effect of ranitidine on twentyfour-hour gastric acidity in infants. J Pediatr 114:472-474

41. Stanciu C, Bennett JR (1974) Oesophageal acid clearing: one factor in the prediction of reflux oesophagitis. Gut 15:852-857

42. Vandenplas $\mathrm{Y}$ (1992) Oesophageal $\mathrm{pH}$ monitoring for gastroesophageal reflux in infants and children. J.Wiley and Sons, England

43. Vandenplas $\mathrm{Y}$, Belli $\mathrm{D}$, Boige $\mathrm{N}$, Bouquet $\mathrm{J}$, Cadranel $\mathrm{S}$, Cezard JP, Chapoy P, Cucchiara S, Dupont C, Gottrand F, Heymans HSA, Kneepkens CMF, Katsiayannikis L, Milla P, Navarro J, Newell SJ, Sandhu BK, Tolboom J (1992) A standardized protocol for the methodology of esophageal $\mathrm{pH}$ monitoring and interpretation of the data for the diagnosis of gastroesophageal reflux. ESPGAN-Society Statement. J Pediatr Gastroenterol Nutr 14:467-471

44. Wilson CM (1987) Methemoglobinemia following metoclopramide therapy in an infant. J Pediatr Gastroenterol Nutr 6:640642 